\title{
LA ARQUITECTURA TEATRAL DEL SIGLO XVIII. EL CASO DE BURGOS Y EL PROYECTO DE FERNANDO GONZÁLEZ DE LARA
}

M. ${ }^{a}$ José Zaparaín Yáñez

René J. Payo Hernanz

Universidad de Burgos

Data recepción: 2019-10-29

Data aceptación: 2020-02-01

Contacto autores: mjzaparain@ubu.es; rpayo@ubu.es

ORCID: https://orcid.org/0000-0002-1443-4964

ORCID: https://orcid.org/0000-0003-2502-8598

\section{RESUMEN}

La arquitectura teatral vivió un gran proceso de renovación en la España del siglo XVIII. Para ello se tomaron como modelo los tratados arquitectónicos franceses e italianos del momento. Algunos notables personajes e instituciones de la política y la cultura, como el conde de Aranda o Jovellanos y la Real Academia de Bellas Artes de San Fernando, impulsaron esta reforma. Este proceso de renovación de la arquitectura teatral no solo se desarrolló en la capital del reino sino también en las capitales de provincia como Burgos. En esta ciudad se trató a lo largo del siglo XVIII de construir un nuevo teatro acorde a los nuevos planteamientos estéticos ilustrados. Para ello, se encargó a Fernando González de Lara un proyecto de nuevo teatro en el que se tomaron como modelo al tratadista español Bails y al francés Patte y cuyos dibujos se conservan en el Archivo Histórico Nacional. Este teatro no se ejecutó por problemas económicos. La reclamación de los honorarios de González de Lara dio lugar a un cruce de correspondencia entre instituciones que nos permite entender la consideración que tenía el trabajo de los arquitectos en el siglo XVIII.

Palabras clave: Arquitectura teatral ilustrada, Burgos, González de Lara

\section{ABSTRACT}

Spain's theatres underwent major architectural renewal in the 18th century. French and Italian architectural treatises of the time were used as a model, and the leading political and cultural characters and institutions of the day, among them the Count of Aranda, Jovellanos and the Royal Academy of Fine Arts of San Fernando, promoted the process of renovation. It played out in the capital of the kingdom and in provincial cities such as Burgos, which tried throughout the 18th century to build a new theatre in line with the new aesthetic approaches. Fernando González de Lara was commissioned with the task of building a new theatre for Burgos. The project was modelled on the treatises written by the Spaniard Bails and Frenchman Patte and its drawings are kept at the National Historical Archive. Financial problems prevented it from ever being built. Gonzalez de Lara's claim for his fees resulted in an exchange of letters that revealed the consideration for architects and their work in the 18th century.

Keywords: theatre architecture, Enlightenment, Burgos, González de Lara 


\section{La renovación del teatro en la España del siglo XVIII}

El siglo XVIII introdujo una revolución en las prácticas escénicas europeas (Franzt 2015). Mientras se codificaba la forma de articular correctamente las piezas teatrales, fue reflexionándose sobre el modo de edificar los ámbitos físicos donde se representaban (Pevsner 1979, 73-106). Algunos grandes teóricos del arte y la arquitectura setecentista, como Francesco Milizia, señalaban que todas las Bellas Artes y las ciencias más útiles debían concurrir en la formación de los teatros (Milizia 1781, 426). España no quedó al margen de este movimiento y con él se vincula el debate entre los "casticistas", defensores de la tradicional actividad dramática española (Erauso y Zabaleta 1750), cuyo marco esencial fueron los patios y corrales de comedias', y aquellos defensores de un teatro más "a la europea" que, apoyándose en el modelo francés, desarrollaban la teoría del "buen gusto" (Rodríguez 2010, 37-55). En este sentido, la polémica que tuvo lugar, en la España tardo-dieciochesca, en torno a los autos sacramentales (Hernández 1989, 185-220), constituye un buen exponente de los afanes renovadores y las resistencias en el mundo dramático hispánico (Varios Autores 1997).

Fue a partir de los años finales de la centuria cuando se gestó una teoría dramática de carácter neoclásico, basada en el concepto de las tres unidades - de acción, de lugar y de tiempo-y en la "imitación de la naturaleza", defendida en España por teóricos como Luzán o escritores como Moratín, Jovellanos o Iriarte, quienes entendieron que algunas obras de nuestros clásicos no se ajustaban a esas normas (Álvarez 1992, 57-73). Para ellos, las piezas teatrales, además de entretener, debían transmitir valores morales y formativos que contribuyeran al avance y mejora social (Vieites 2019, 199-224). Ello se vio respaldado por la creación, en noviembre de 1799, de una Junta de Reforma (Soria 2009, 9-32.) de la que fue nombrado presidente Leandro Fernández de Moratín, quien dimitiría sin poner en marcha la prohibición de representar una buena parte de las obras dramáticas del Siglo de Oro Español aunque sus sucesores sí que actuarían en este sentido, favoreciendo así una mayor penetración del teatro francés (García 1989, 299-305).
Por su parte, Gaspar Melchor de Jovellanos, con el fin de propiciar acciones educadoras a través del teatro ${ }^{2}$, promueve una serie de medidas que debían seguir los dramaturgos y establece las características de los actores, al igual que harán otros críticos dieciochescos (Carnero 1994, 3767). También insistía en cómo organizar los nuevos espacios dramáticos, pues juzgaba indecorosos los antiguos teatros y su "aparato escénico" ${ }^{\text {. }}$. A su vez, las autoridades ilustradas trataron de evitarlos desórdenes que podían producirse en las representaciones al regular las prácticas escénicas y el comportamiento del público ${ }^{4}$. Todo ello se vio acompañado, desde mediados del siglo XVIII, por una incipiente teoría sobre la arquitectura dramática5. Ya José de Hermosilla, hacia 1750, en su tratado manuscrito de Arquitectura Civil (Rodríguez 2019, 267-311), hablaba de la revolución que estaba produciéndose en las construcciones tras la llegada de los Borbones y de las representaciones musicales a la italiana, que habían hecho cambiar los modelos de teatro, abandonándose los viejos corrales (Hermosilla 1750, 301-2). A pesar del retraso con el que llegaron las influencias europeas y del carácter periférico que, en relación con las italianas y francesas en los años iniciales del siglo XVIII, define a muchas de las creaciones arquitectónicas de este género en España, sí que podemos señalar la existencia de algunas experiencias muy significativas en estos años (García 1994, 214).

Prueba de este interés es, igualmente, la recepción de obras tratadísticas extranjeras, como el Essai sur l'Architecture theâtrale de Pierre Patte -publicado en París en 1782, que tuvo una notable incidencia en la práctica de la arquitectura teatral hispana tardodieciochesca (García 1994, 225) (fig. 1)-. A su vez, el tratado de Francesco Milizia -editado en Roma en 1771 y Venecia en 1773 (Milizia 1773) - fue traducido al castellano en 1789 (Milizia 1789). En él se hacía un análisis histórico y teórico sobre las características de las representaciones dramáticas y sus géneros y aportaba recetas prácticas para la edificación de los teatros, en las que distinguía entre antiguos y modernos, logrando una notable influencia en teóricos hispanos como Ortiz y Sanz y en arquitectos como Silvestre Pérez (Sambricio 1975, 75). En España, las principales reflexiones, además del citado manuscrito de Hermosilla, aparecen en la 


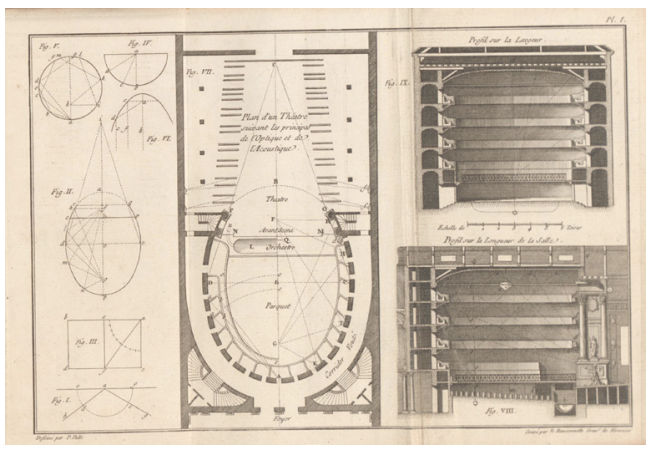

Fig. 1. Patte, Pierre, Planta y secciones de un teatro, 1782. Essai sur l'Architecture theâtrale. París: Chez Moutard, p. 210

obra de Benito Bails, de ya avanzada la segunda mitad de la centuria, siendo sus consideraciones deudoras de las de Pierre Patte (Bails1783, 87090), trasladando sus aspectos gráficos y textuales casi de manera mimética 6 (fig. 2).

Como muy bien ha señalado García Melero, no existió una tipología única y universal del teatro (García 1994, 215), aunque, de forma progresiva, se fue codificando la manera en la cual debía plantearse, viéndose necesario establecer dos ámbitos esenciales: el dedicado al público y la caja escénica (Leóny Sanz 1994, 1.060-65). Siguiendo la tradición arqueologista greco-romana? se planteaba la posibilidad de repetir esos modelos, es decir, con espacio dedicado al público en forma semicircular. Pero, poco a poco, fue evolucionándose hacia la planta en " $U$ ", para pasar, como señala García Melero, a la de herradura en el barroco académico-cortesano y a la elíptica y oval longitudinal truncadas por el escenario en el pleno siglo XVIII, culminándose en la de forma de campana en el periodo rococó. En el Neoclasicismo algunos teóricos trataron de volver a la simplicidad del semicírculo o a la forma en " $U$ ", aunque también otros, como Patte, defendieron las soluciones ovales por razones fundamentalmente acústicas y ópticas (García 1994, 216). Mientras, fue generalizándose el modelo vertical en lo que se refiere a la ubicación de los espectadores en el patio y en los palcos. Para el caso español, ya José de Hermosilla, hacia 1750, se decantaba por un tipo con estas características que aparece reflejado

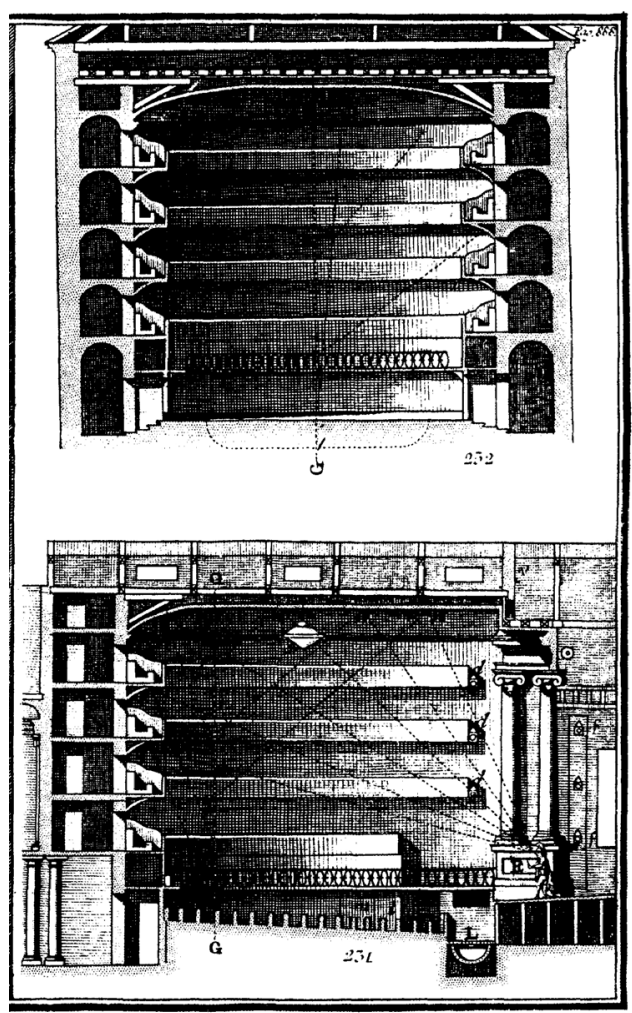

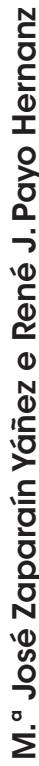

Fig. 2. Bails, Benito, Secciones de un teatro, 1783. Elementos de Matemáticas, T. IX, Parte Primera. Madrid: Imprenta de la viuda de Ibarra, p. 889

en su tratado manuscrito (Hermosilla 1750, 307) (fig. 3).

Por su parte, las cajas escénicas fueron objeto de atención, dada la importancia otorgada a las nuevas escenografías de las piezas dramáticas u operísticas $^{10}$. Algunos tratadistas comenzaron a sustituir las antiguas escenas-fachada, de tradición clásica, por profundas escenas abiertas cuyas cajas acogían complejas tramoyas. Respecto a este último aspecto, fue el presidente del Consejo de Castilla, el conde de Aranda -preocupado por la renovación de la arquitectura española (Rodríguez y Sambricio 1998, 147-71)- una de las figuras que, desde un punto de vista político, más influyó en la actualización de las escenografías teatrales al ordenar, en 1763, a la Junta de Teatros, que los paños de las escenografías fueran sustituidos por decoraciones pintadas y que las orquestas se adelantaran hacia el público". 


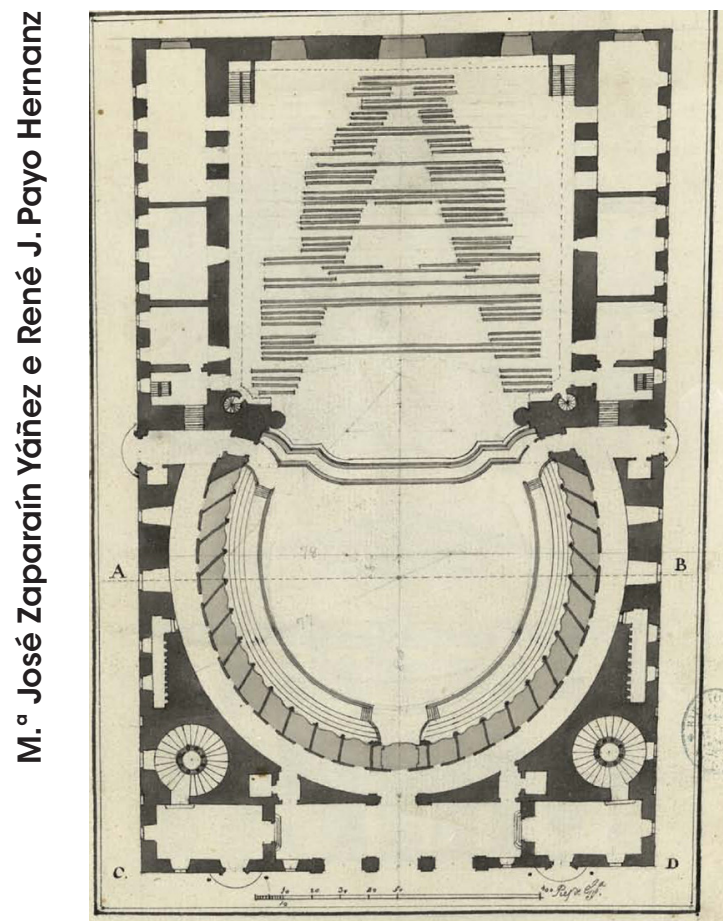

Fig. 3. Hermosilla, José de, Planta de un teatro, 1750. Architectura Civil, fol. 193, Biblioteca Nacional, MSS-7573, Madrid

Prueba de la relevancia concedida a todos estos aspectos son aquellos exámenes y premios de arquitectura convocados por la Real Academia de San Fernando, durante los siglos XVIII y XIX (Balsalobre 1998, 261-86), en los que se pedía la proyección de un teatro, empleándose modelos bien a la italiana, de tradición clásico-palladiana que siguen las propuestas de Milizia, o a la francesa de Patte, con plantas de auditorio ovales o elípticas. Así, por ejemplo, Juan Barcenilla diseñó, en 1770, una obra a la grecorromana con ecos palladianos ${ }^{12}$. Algo similar realizó Ramón Alonso, en 1772, pero desarrollando los balcones en altura, a modo de palcos, por encima del graderío ${ }^{13}$, y lo mismo haría, en 1790, Mateo Vicente Tabernero ${ }^{14}$, mientras que Juan Milla planteó, en 1772, un teatro en forma de " $U$ " ${ }^{15}$. Todo ello no hace más que expresar el rico debate sobre la forma de construir los espacios dedicados a la práctica dramática en el siglo XVIII (Peruarena 2013, 22151) (figs. 4 y 5).

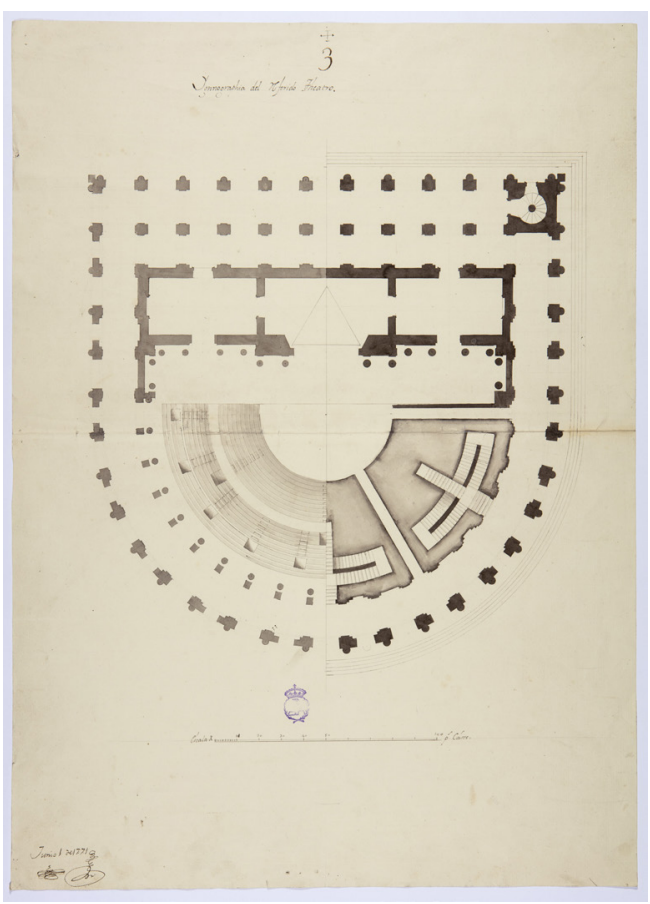

Fig. 4. Barcenilla, Juan, Planta de un teatro, 1770. Museo de la Real Academia de Bellas Artes de San Fernando, A-3269, Madrid

Igualmente, hubo razones de seguridad detrás del interés por reformar la arquitectura teatral, puesto que fueron frecuentes los incendios que asolaron las viejas y endebles estructuras de madera de los patios de comedias. Especial trascendencia tuvo el incendio del Coliseo de Zaragoza que ardió, en su totalidad, la tarde del 12 de noviembre de $1778^{16}$. Fue tanta la repercusión de este trágico accidente que inspiró obras pictóricas y poéticas, las cuales, en clave prerromántica, transmitían, por un lado, terror y, por otro, atracción hacia un suceso que quienes lo contemplaron no dudaron en juzgar como grandioso (Viamonte 2013, 93-111; Alier 1996, 157164.). Los incendios hicieron que el Consejo de Castilla ${ }^{17}$ y teóricos como Bails ${ }^{18}$ se plantearan las condiciones de seguridad de estas edificaciones en cuya construcción emplearían los materiales más resistentes, estando dotadas de salidas de humo y puertas preparadas para una rápida evacuación.De este modo, en los nuevos edificios teatrales se unían los tres conceptos que definían 


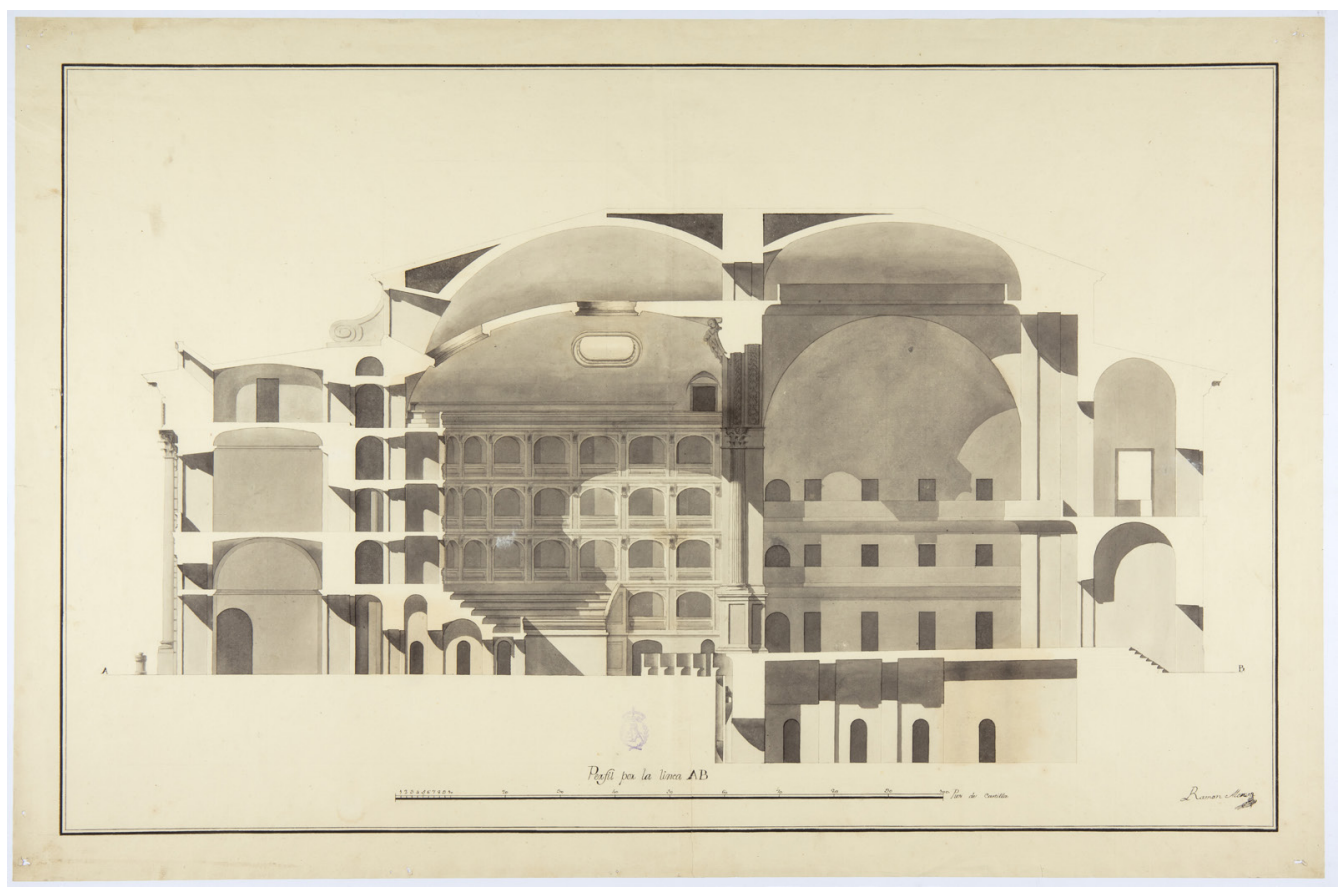

Fig. 5. Alonso, Ramón, Sección de un teatro, 1772. Museo de la Real Academia de Bellas Artes de San Fernando, A-3275, Madrid

la arquitectura vitruviana: la utilitas, la firmitas y la venustas (González 1993, 37-38).

Todas estas preocupaciones también encontraron eco en Burgos, centrándose en la disponibilidad de un edificio para este fin, sus características, emplazamiento e, incluso, en su propia necesidad. Las tensas discusiones entabladas por los capitulares de la vieja Caput Castellae a este respecto manifiestan, a su vez, las dificultades que los antiguos cascos urbanos tuvieron para poder acoger, con garantías, un establecimiento teatral conforme a las nuevas exigencias formuladas a lo largo de la centuria.

\section{Los patios de comedias en Burgos hasta 1796}

Desde 1587, la ciudad castellana disponía de un patio de comedias que ocupaba la llamada casa de los Niños de la Doctrina, ubicándose en el antiguo Corralón de las Tahonas. Estaba emplazado extramuros, en las inmediaciones de la iglesia de San Gil, en una posición claramente periférica (Ibáñez 1990, 21), pero beneficiada por ser zona de posadas y mesones (Miguel 1991, 249-264, 1992, 45-74). A mediados del Setecientos, comenzó a ponerse en cuestión su existencia, puesto que habían sido prohibidas las funciones cómicas en la ciudad y el arzobispado (Miguel $1994,66)$. A ello se sumaba la exitosa predicación de la Santa Misión que el dominico Antonio Garcés protagonizó durante el otoño de 1752, exponiendo el conocido tópico moralista contrario al teatro ${ }^{19}$. Este pensamiento se enmarcaba en una campaña generalizada en toda España contra el teatro (Miguel 1994, 66) que, en Burgos, trajo como resultado el acuerdo tomado el 2 de diciembre de 1752 para derribar el patio de comedias ${ }^{20}$, careciéndose desde entonces de un espacio apropósito donde celebrar las representaciones. De ahí que, cuando la Real Orden de 7 de febrero de 1772 posibilitara a los concejos invertir su liquidez económica en obras públicas, se aprobara, no sin oposición, la construcción de un nuevo edificio consistorial que acogiera un teatro ${ }^{21}$. De este modo, no solo se mantenía el sentido multifuncional propio de los consistorios de la Edad Moderna en las medianas y pequeñas 
poblaciones, sino que reforzaba el carácter lúdico de la plaza como lugar de celebraciones y festejos (Navascués 2002, 10-12).

Aunque este acuerdo no se materializaría, Burgos logró contar, en la década de los años 70 , con un patio de comedias "provisional" instalado en el solar del antiguo Mesón de los Reyes, en la calle Cantarranas la Mayor, actual Almirante Bonifaz. Lo promovió el maestro de obras Agustín Pérez, ocupando un solar del mayorazgo del marqués de Villacampo, miembro del regimiento burgalés. Era un local entre medianeras, de reducidas dimensiones y complicado acceso, en una zona de angosto viario. Su planta se disponía en profundidad, perpendicular a la calle, y su interior quedaba articulado en pequeños aposentos, siendo la circulación espacial incómoda, dada la estrechez de unos pasillos levantados con tablazones y reducidos a oscuros "callejones" por donde solo cabía una persona ${ }^{22}$, habiéndose erigido sin cimentación, en madera y expuesto a las humedades de un terreno por el que discurría la esgueva de la Moneda23. De ahí que sus condiciones, especialmente tras el incendio del Coliseo de Zaragoza, fueran objeto de duras críticas. Por ello, el capitular Juan Antonio Santa María y el diputado del común Juan del Val realizaron un proyecto para sustituirlo que sometieron a la consideración de la Ciudad. Esta propuesta, que tampoco se realizó, se ajustaba, en su opinión, a la normativa del Consejo de Castilla al contar con cuatro amplias salidas y eficaces "respiraderos" y tener fácil acceso a una bomba de agua, cumpliendo su emplazamiento, próximo al río Pico, con las preferencias de la institución madrileña ${ }^{24}$.

Sin embargo, no es hasta noviembre de 1780 cuando se pide a los alarifes de la ciudad, Julián Arbaiza y Luis Céspedes, que examinen el teatro provisional, siendo su dictamen positivo, lo cual permite sospechar que las descalificaciones recibidas buscaban desautorizar un local de carácter particular que acogía funciones públicas $y$, seguramente, no reunía unas condiciones de decoro acordes a la renovación y modernización que Burgos estaba experimentando (Iglesias 1978). En cualquier caso, los maestros centraron su examen en cuestiones relativas a la seguridad, indicando que era imprescindible dotarlo de un tragaluz y que las puertas se abrieran hacia la calle. Mientras el corregidor intentaba que el propietario acometiera las mejoras, varios miembros del Concejo se dirigieron al Consejo de Castilla para insistir en sus deficiencias. Ello no detuvo la realización de las obras propuestas por Arbaiza y Céspedes quienes, al examinarlas, declararon su idoneidad25.

Las funciones teatrales se retomaron y devengaron, en pocos meses, un importante beneficio, lo cual animó al Concejo, tras un intenso debate, a adquirir el patio de comedias provisional en octubre de 1781. Tras ello, el Concejo llevó a cabo diversas mejoras que desembocaron en una nueva polémica con quienes consideraban que resultaban inútiles e incluso perjudiciales, pues solo se había disimulado la lobreguez del sitio mediante papeles y lienzos pintados que constituían otro "...pábulo más [que] se ha añadido al fuego, si como es fácil ocurriera tal desgracia". De ahí que se vuelve a pedir a los alarifes que declaren si tenía la seguridad, decencia, desahogo y comodidad pública requeridas, descartando los maestros "...que pueda acaecer algún peligro al presente..." ${ }^{26}$.

En septiembre de 1786, antes de que entrase a actuar una compañía, se reabre el debate, siendo los maestros Luis y Francisco Céspedes quienes lo revisaron y dieron el visto bueno ${ }^{27}$. Sin embargo, las continuas quejas de algún miembro del regimiento y las desavenencias con el propietario del solar obligaron a su cierre ${ }^{28}$, quedándose Burgos sin ningún establecimiento teatral. Fracasada la iniciativa de algún autor de comedias para hacer un teatro a su costa22, pasaron varios años hasta que tan controvertido tema fuera retomado por la vieja Caput Castellae.

\section{El proyecto de Fernando González de Lara}

Tras las estériles polémicas y exiguas actuaciones desarrolladas por el Concejo de Burgos a este respecto, fue, en 1796, cuando se encargó a Fernando González de Lara que llevara a cabo un proyecto a fin de dotar a la ciudad, de manera definitiva, de un teatro apropiado a sus necesidades. González de Lara fue, sin duda, el profesional más importante en el ejercicio de la arquitectura en el Burgos del último tercio del siglo XVIII (Cadiñanos 1985, 57-78; Payo 2005, 99-103; Iglesias 2011, 94-5), siendo, en esos mo- 
mentos, el único arquitecto titulado por la Real Academia de Bellas Artes de San Fernando en la ciudad, lo cual, en teoría, le confería el privilegio de ser el tracista de sus principales obras públicas (Quintana 1983, 100-01). Transformador y generador de espacios urbanos como el Paseo del Espolón (Iglesias 1978, 47-50), diseñador de las nuevas casas consistoriales (Payo 2007, 190-211), de iglesias como la de San Juan de Huérmeces que evidencia el conocimiento de las grandes obras clásicas como el Panteón (Ibáñez 1976, 813-18), ejecutor de notables intervenciones en la catedral, como la polémica reforma de su portada principal (Iglesias 1978, 63-65; Nieto 1999, 339-76), de retablos (Payo 1997, 379-93) y director de obras públicas por toda la provincia y zonas limítrofes (Sambricio 1986, 336-40; Cadiñanos 1985, 57-78; Iglesias y Zaparaín 2018, 53-99), se hallaba, en 1796, en el ocaso de su carrera, enfermo y cuestionado en algunas de sus actuaciones. El cruce de cartas entre el arquitecto, el Consejo de Castilla, la Academia y el Regimiento nos ayudará a comprender no solo la precaria situación económica del tracista, quien se aferraba al pago de sus dibujos para subsistir, sino, también, la diferenciada consideración que cada una de estas instituciones daba al ejercicio del diseño arquitectónico.

A principios de abril de 1796, el intendente corregidor convocó un regimiento para analizar la posibilidad de construir un nuevo espacio escénico, ante los inconvenientes de orden público y quejas que la carencia de los espectáculos teatrales venía ocasionando. Dada la seriedad del tema, hubo una nueva sesión pasados unos días, en la cual volvió a reproducirse la polémica entre quienes, como Bernardo Íñigo de Angulo, desaprobaban su construcción, alegando los habituales daños morales, sin olvidar los problemas de su elevado coste y mantenimiento, y aquellos que, como el marqués de Fuentepelayo, lo estimaban imprescindible para una localidad en expansión, que había recuperado su carácter estratégico en las comunicaciones entre el norte y la corte, convirtiéndose, además, en un destacado centro burocrático, donde se aglutinaba una importante población militar y con una juventud necesitada de entretenimientos ${ }^{30}$. Finalmente, se aprobó la realización de un teatro acorde a la importancia de la ciudad y ajustándose a las disposiciones establecidas tras el incendio del Coliseo de Zaragoza.

No sin debate, se optó por levantarlo con vocación de permanencia y se barajaron hasta seis opciones para su emplazamiento, buscando siempre la cercanía con una corriente de agua: el Corral de los Infantes -junto al Arco de Santa María-, Cantarranas la Mayor -en el denostado emplazamiento del patio de comedias de Agustín Pérez-, a la salida de la Plaza de Margarita -frente a la esgueva que pasaba junto al convento de la Santísima Trinidad-, las llamadas "casas quemadas" de la parroquia de San Lesmes y Casilda de la Moneda en la calle La Puebla -por donde también discurría una esgueva y se podían establecer cuatro salidas capaces-, las Panaderías -en el entorno de la Plaza del Mercado Menory donde estuvo la Botillería -entre la Plaza del Mercado Mayor y la del Mercado Menor-, propiedad del común e inmediata a una esgueva-31. Todas las posibilidades contempladas estaban en zonas próximas a las antiguas murallas o fuera de ellas, lo que revela la dificultad de encontrar, en el centro de la ciudad, solares con las condiciones precisas para las dimensiones de estos edificios. Con amplio consenso, el emplazamiento elegido fue el del Corral de los Infantes, donde el Concejo tenía propiedades y, según pensaba Angulo, podría ampliarse su superficie, agregando el solar correspondiente a la muralla, sin olvidar su proximidad al Arlanzón, los amplios accesos que era factible practicar y su ubicación en una zona bastante céntrica de la población ${ }^{32}$.

Su elección revela el concepto y la imagen de ciudad que venía desarrollándose a lo largo de las últimas décadas. En este periodo había sido objeto de atención preferente el sector comprendido entre los puentes de San Pablo y Santa María, experimentando una intensa renovación, según los criterios del Reformismo llustrado, al mismo tiempo que la antigua Caput Castellae se abría hacía el exterior. De ahí que, progresivamente, se fuera prescindiendo del dogal de las murallas y ya sobre la línea del lienzo sur se hubiesen levantado la Cárcel y el Consistorio (Iglesias 1978, 71-74; Payo 2007, 190-211) cuya cuidada disposición hacia el río había generado el trazado del Paseo del Espolón. A este también quedaba orientada la Escuela de Dibujo que, entonces, construía el 
Consulado (Ibáñez 1982, 34-70). De este modo, el teatro actuaría de contrapunto a la Cárcel, emplazada al principio del Paseo y en comunicación con el Puente de San Pablo.Además, quedaría situado en uno de los puntos de mayor dinamismo de la ciudad, inmediato a la Catedral y al Puente de Santa María que daba acceso a la Plaza de Vega donde, recientemente, se había instalado el moderno parador del Consulado para atender a los muchos viajeros que llegaban a Burgos (Iglesias 1978, 102-03).

Más desencuentros provocó la elección del profesional que debía proyectarlo. Angulo tenía claro "...que para que se consiga el acierto, el buen gusto, solidez y ermosura..." solo podía elegirse a González de Lara. Se cumplirían, así, las disposiciones regias que ordenaban la realización de las obras de carácter público por un arquitecto con el reconocimiento de la Real Academia de Bellas Artes de San Fernando y bajo la supervisión de esta, (Bédat 1989, 371-98) pero como sus relaciones con el Concejo no habían sido siempre fáciles, y se desconfiaba en su criterio a la hora de tasar la cuantía de las obras, también propone que se consulte a otro profesional de prestigio. Precisamente, por los problemas surgidos en su tasación del Paseo del Espolón, fueron muchos los capitulares que se opusieron a su elección, aunque, finalmente, a él fue encomendado el proyecto ${ }^{33}$.

Pocos días más tarde, González de Lara presentaba las conclusiones de su estudio. Consideró que, aun ocupando todas las propiedades que tenía allí la Ciudad y el terreno de la muralla, el solar no era suficiente para un patio de comedias de tamaño medio, adecuado a las necesidades de la población. Esta declaración dio paso a un nuevo debate sobre el emplazamiento, eligiéndose "...el sitio erial que hace sobre el puente de la cava...", al tenerse en cuenta su proximidad al río y la facilidad para practicar "... salidas desembarazadas". Sin embargo, algún capitular dejó constancia de su disconformidad, por hallarse alejado del entorno del Espolón y de la Plaza del Mercado Menor ${ }^{34}$.

A finales de octubre, la propuesta, con un coste de 247.691 reales, ya estaba elaborada y se tramitaba ante el Consejo de Castilla que, a principios del año siguiente, la desautorizó, fun- damentalmente por su elevado coste, aceptando, en cambio, la construcción de una obra más modesta en la calle La Puebla35, en la cual no intervino González de Lara (Iglesias 1978, 77-79). Este rechazo no evitó que el autor del proyecto intentara cobrar su realización y en mayo solicitó que fuera la Real Academia de Bellas Artes de San Fernando la encargada de estimar su precio pues, desde el primer momento, el Concejo se mostró contrario a la remuneración, al considerar que, cuando elaboró los planos, percibía un sueldo diario por atender las obras del Paseo del Espolón, por lo que "defraudaba" a la Ciudad con su pretensión, no perdiendo ocasión algún capitular de recordar el error del arquitecto en sus tasaciones, por lo cual no era digno de ninguna consideración. El arquitecto se vio obligado a insistir en múltiples ocasiones que eran rechazadas sistemáticamente por el Concejo, por lo cual decidió exponer su situación ante el Consejo de Castilla y la Academia a quien pidió disculpara los posibles defectos de unos planos realizados con más de 70 años $^{36}$.

La Academia, antes de dictaminar, quiso que el arquitecto comunicara al Consejo de Castilla en cuánto estimaba su trabajo, lo que le llevó, en agosto de 1804, a enviarle los borradores de los planos, pues los originales habían sido devueltos al Ayuntamiento, el cual primero se había negado a entregarlos, para después alegar su extravío. Los evaluó en 6.000 reales, cantidad que fue considerada justa por la Comisión de Arquitectura de la Academia ${ }^{37}$. La Ciudad pospuso aceptar esta resolución y González de Lara estaba convencido que el Concejo actuaba de mala fe, sin tener en cuenta sus graves dificultades económicas y sus "...continuados achaques con su avanzada hedad..." que le impedían trabajar. No mentía el académico sobre su salud, pues falleció mientras el regimiento burgalés seguía dilatando el proceso, aunque la Academia se ratificaba en su tasación ${ }^{38}$. Todo ello dio lugar a una Real Provisión de 6 de octubre de 1806 por la que se exigía al Concejo que pagase a la viuda del arquitecto ${ }^{39}$.

Tras esta ardua polémica subyace la diferenciada forma que tenían las partes implicadas de entender el ejercicio de la arquitectura. Así, el Concejo no aceptaba la necesidad de premiar o remunerar "...una ocupación para la que le so- 
brava tiempo en las horas que devía ocupar..." en el cuidado del proyecto del Espolón. Además, en su opinión, "... los citados planos le pudieron costar poquísimo tiempo y trabajo, respecto que según noticias que tiene el Ayuntamiento, no hizo otra cosa que copiarlos de un libro que se le entregó por uno de sus capitulares, extendiendo las dimensiones en un campo abierto en aquel sitio no presentaba dificultad alguna" 40 .

Por el contrario, para González de Lara y la Academia, una obra de esta naturaleza requería mucho estudio y no se podía dejar en manos de profesionales no cualificados, insistiéndose en que "Si entendiese algo el Ayuntamiento del estudio y trabajo que trae consigo la ydea de un edificio especialmente de un teatro como el que se trata no se hubiera desentendido quando se le pidió su justa paga y hubiera conocido que tampoco podían sufragar semejante trabajo..." con la cantidad que se le abonaba por dirigir el Paseo del Espolón. La Academia, a través de su secretario, Isidoro Bosarte, criticó ácidamente la situación motivada, a su juicio, por no entregarse los planos de las obras públicas a la institución académica para su examen, siendo el cumplimiento de las órdenes regias, "...muy necesario no solo para que sirva de obstáculo a la ignorancia sino también a la arbitrariedad de los Ayuntamientos", como parecía haber sido el caso de la antigua Caput Castellae ${ }^{41}$, alentada por el ambiguo papel jugado por el Consejo de Castilla. Cierto es que esta institución debía respetar la supervisión de las obras públicas por parte de la Real Academia, pero también que intentaba seguir manteniendo sus antiguas prerrogativas de control bajo el pretexto de la búsqueda de la economía (Bédat 1989, 376-78).

En paralelo al encargo hecho a este arquitecto, el Concejo dispuso la realización de un patio de comedias provisional en la calle La Puebla diseñado por Agustín Pérez, el cual, aprobado por el Consejo de Castilla, sí que se llevó a efecto42, estableciéndose que su coste no excediera de los 46.600 reales $^{43}$. El fallecimiento de Agustín Pérez hizo que se encomendara la obra al alarife de la ciudad Francisco Céspedes ${ }^{44}$ quien introdujo notables y significativas reformas y mejoras ${ }^{45}$. Estas duplicaron el presupuesto, de cuya diferencia no se hizo cargo el Concejo46, lo que obligó a Cés-

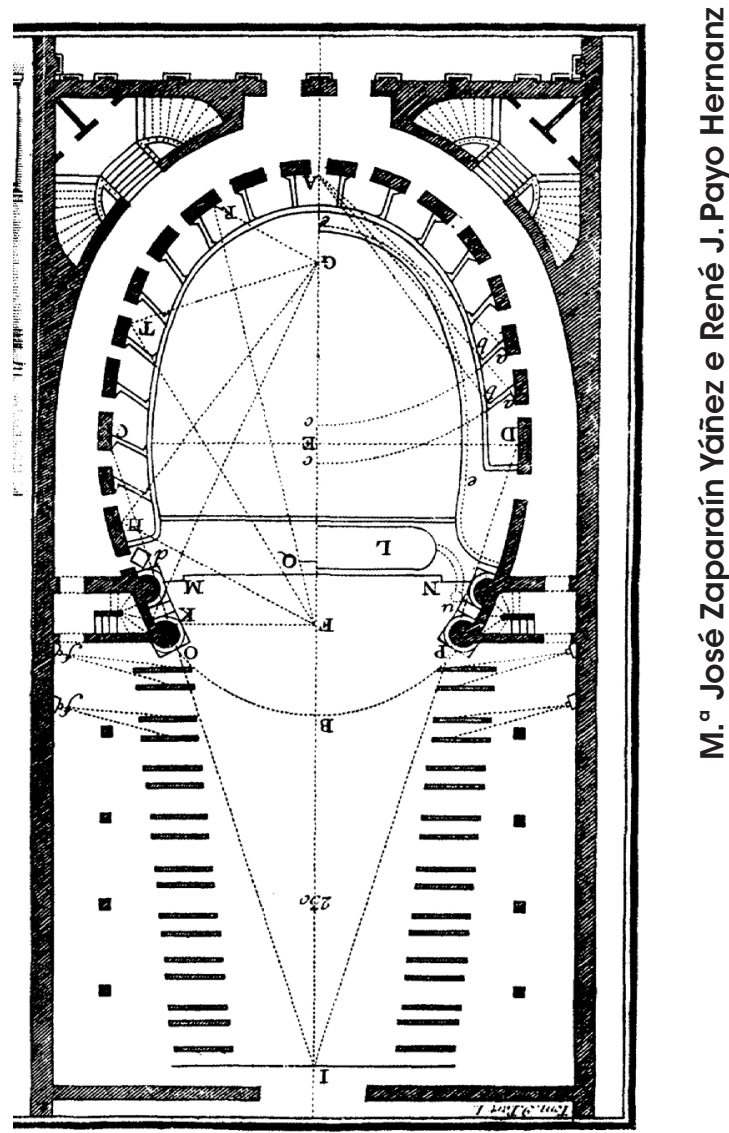

Fig. 6. Bails, Benito, Planta, 1783. Elementos de Matemáticas, T. IX, Parte Primera. Madrid: Imprenta de la viuda de Ibarra, p. 889

pedes a elevar sus quejas al Consejo de Castilla para intentar su cobro ${ }^{47}$. Este edificio nunca tuvo condiciones óptimas para las representaciones ${ }^{48}$ y por eso no extraña que Isidoro Bosarte, cuando intervino en la reclamación de González de Lara ante la Academia, hiciera ver el despropósito que suponía que "...el común de Burgos está obligado a pagar unos planos que no se pusieron en execución, hallándose ahora con una obra construida por otros dibujos mas malos que los que desechó", siendo "...obra mezquina sin las conveniencias necesarias a su destino..." 49. 


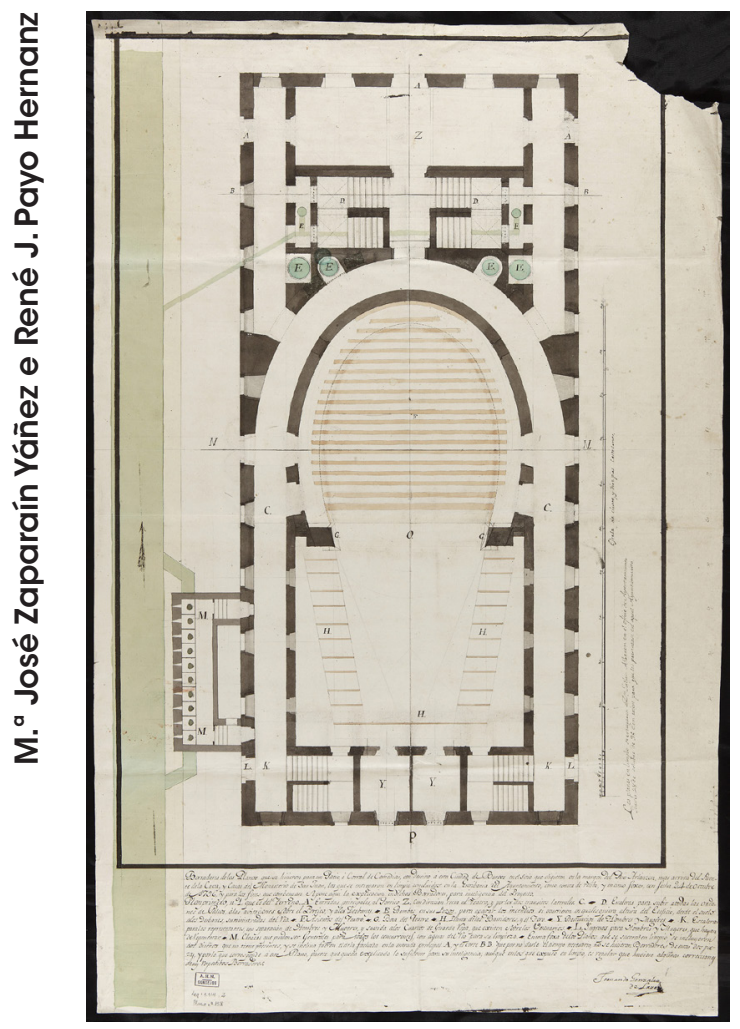

Fig. 7. González de Lara, Fernando, Planta para un teatro en Burgos, 1796. Archivo Histórico Nacional, Sección MPD 158, Madrid

\section{Los diseños de González de Lara en el con- texto de la arquitectura teatral española del siglo XVIII}

La propuesta de Fernando González de Lara de1796 se plasmó "...en cinco pliegos de papel de marca imperial y un topográfico pequeño...", diseñándose con "...escrupulosa exactitud y con arreglo a los preceptos del arte...", atendiendo a las disposiciones de seguridad establecidas por el Consejo de Castilla ${ }^{50}$. Nos es conocida a través de los borradores enviados por el autor al Consejo de Castilla cuando reclamó su pago, hoy custodiados en el Archivo Histórico Nacional. Efectuados en tinta negra, verde y rosácea y aguada gris, son la planta, dos secciones, una fachada lateral y el esbozo del arranque de los arcos, cuya rígida traza y somera utilización del sombreado revelan su condición de estudios previos ${ }^{51}$. Estos diseños le ubican muy bien en el conocimiento de las in-

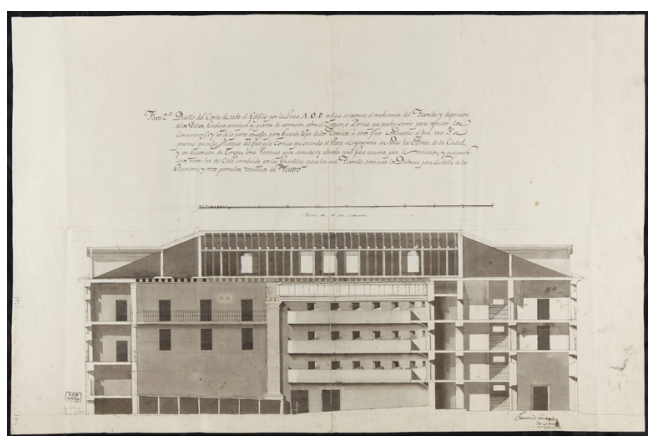

Fig. 8. González de Lara, Fernando, Sección longitudinal para un teatro en Burgos, 1796. Archivo Histórico Nacional, Sección MPD 159, Madrid

novaciones arquitectónicas teatrales que estaban teniendo lugar en la España tardo dieciochesca, el cual se produciría a través de la literatura tratadística y de sus contactos con la Academia de San Fernando de la que era académico de mérito. Además, el libro facilitado por un miembro del Concejo burgalés cuando estaba haciendo el proyecto y en el que se inspiró muy bien pudo ser el tratado de Bails (fig. 6).

González de Lara traza una planta inscrita en el interior de un rectángulo que queda dividido en tres secciones. La primera está conformada por el gran vestíbulo que daba acceso a dos escaleras divergentes a través de las que podía llegarse hasta la zona de palcos. Se concedió, por parte del tracista, un singular carácter representativo a este primer espacio de relación que debía mostrar la grandeza del nuevo edificio. En este sentido, parece hacerse eco de la crítica de Milizia respecto al escaso protagonismo que tenían las entradas, vestíbulos y escaleras de los teatros tratando, así, de remediarlo52. La segunda zona era el espacio destinado al público que, siguiendo modelos franceses -como el de Pierre Patte en su Essai sur l'Architecture theâtrale - se desarrollaba en forma de herradura. Ya, en 1770, la Academia de Bellas Artes premió el diseño de Juan Barcenilla que tenía una incipiente forma de herradura53. Muy probablemente González de Lara conoció la propuesta de Bails (Bails 1783, 889) para quien la configuración del patio debía garantizar una perfecta visión y audición ${ }^{54}$. Finalmente, la tercera zona en la que se articulaba la planta es la gran caja escénica, que queda reflejada en el diseño 


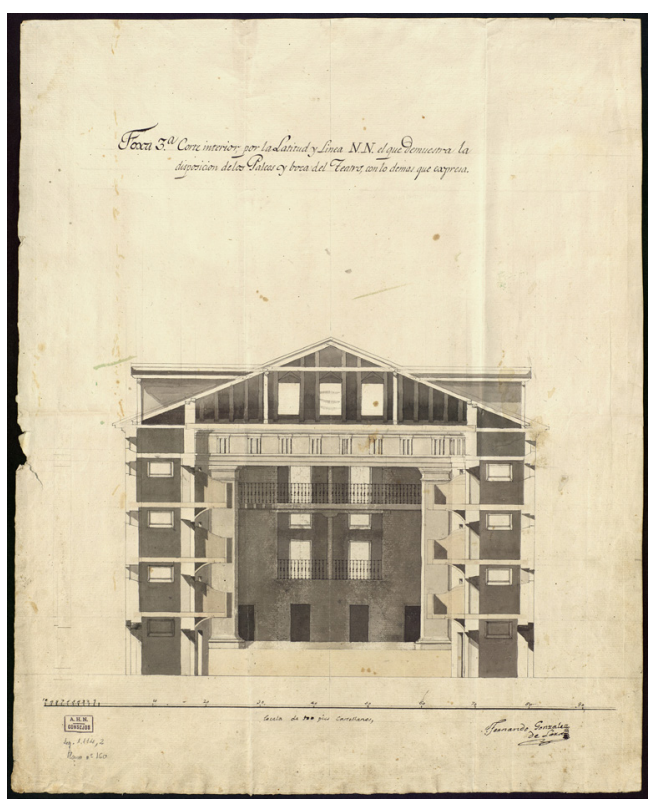

Fig. 9. González de Lara, Fernando, Sección transversal para un teatro en Burgos, 1796. Archivo Histórico Nacional, Sección MPD 160, Madrid

mediante la leyenda planta de los bastidores y foso. Igual que propone Bails, del que González de Lara es deudor, existe una clara relación entre la zona de los espectadores y el escenario, siempre a la búsqueda de una perfecta conexión visual de aquellos con este ${ }^{55}$ (fig. 7).

Por su parte, la sección longitudinal muestra con detalle el desarrollo en altura de la planta, evidenciando que la distribución de los espacios del teatro -de accesos y representativo, de espectadores y caja escénica-resultaba casi por igual, teniendo paralelismos con las propuestas de Bails que, en su tratado, dio una gran relevancia a la colocación de los palcos (Bails 1783, 880). Al mismo tiempo que la sección transversal revela la importancia concedida a la caja escénica y a la organización de los palcos, permite conocer que la estructura de entrecubierta se planteaba como un espacio aprovechable (figs. 8 y 9).

Lamentablemente, entre los planos enviados al Consejo de Castilla no se encuentra el alzado de la fachada principal que, sin duda alguna, sería especialmente significativo. A través de la planta, sa-

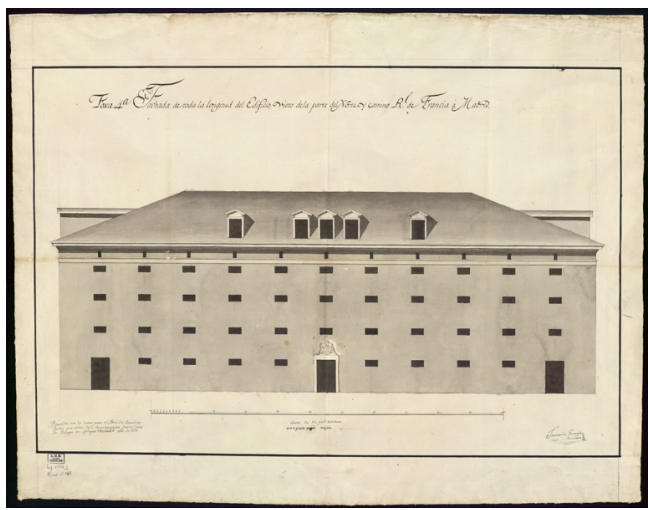

Fig. 10. González de Lara, Fernando, Alzado de la fachada norte para un teatro en Burgos, 1796. Archivo Histórico Nacional, Sección MPD 161, Madrid

bemos que tres puertas daban acceso al vestíbulo principal y que otras dos en los extremos permitían el paso a la zona destinada al público en la zona baja. Quizá esta obra pudiera seguir el modelo de los tratadistas como Hermosilla, articulándose con varios órdenes de columnas superpuestos. Sí que se conserva el alzado de la fachada norte del edificio que estaba orientada hacia el Camino Real a Madrid. Contaba con tres puertas de acceso, una central y dos en los extremos. La central quedaba rematada con el escudo de la ciudad, flanqueado por dos festones que le conferían una imagen semejante a la que presenta este elemento heráldico en los laterales del primer cuerpo de la fachada de las nuevas casas consistoriales diseñadas por el propio González de Lara. La fachada muestra numerosas ventanas de disposición predominantemente horizontal, coronándose la cubierta con varias buhardillas (fig. 10). El carácter sumamente sobrio, de rígida planimetría, nos hace plantearnos hasta qué punto el arquitecto no se inspiraría en el revivalismo neoescurialense (Rodríguez 2019, 403-50) que algunos profesionales, como Ventura Rodríguez o Juan de Villanueva, estaban llevando a cabo en los años finales del siglo XVIII. En concreto, hallamos bastantes paralelismos con los diseños que Juan de Villanueva realizó para el entorno de El Escorial en donde siguió los modelos de Juan de Herrera con cuyo estilo armoniza perfectamente (Sambricio y Herrero1988, 189-205; Monleón 1988). 


\section{NOTAS}

Entre los estudiosos de este asunto se encuentra René Andioc, Teatro y sociedad en el Madrid del siglo XVIII (Madrid: Castalia, 1988).

2 "...un teatro que aleje los ánimos del conocimiento de la verdad fomentando doctrinas y preocupaciones erróneas, o que desvíe los corazones de la práctica de la virtud excitando pasiones y sentimientos viciosos, lejos de merecer la protección merecerá el odio y la censura de la pública autoridad...": Gaspar Melchor de Jovellanos, Memoria para el arreglo de la policía de los espectáculos y diversiones públicas y sobre su origen en España (Madrid: Ediciones Cátedra, 1983), 130.

3 "El teatro es el domicilio propio de todas las artes; en él todo debe ser bello, elegante, noble, decoroso y en cierto modo magnífico, no sólo porque así lo piden los objetos que presenta a los ojos, sino también para dar empleo y fomento a las artes de lujo y comodidad, y propagar por su medio el buen gusto en toda la nación": Jovellanos, Memoria para el arreglo de la policía de los espectáculos y diversiones públicas y sobre su origen en España, 139-40.

${ }^{4}$ Novísima Recopilación de las Leyes de España, Libro VII, Título XXXIII, Leyes XI-XII.

5 Tendremos que esperar al tratado de José Hermosilla (1750) para que comience a existir una preocupación teórica sobre el tema del teatro. Resulta curioso que el tratado de Brizguz y Bru (1738) no recogiera este tema: Athanasio Genaro Brizguz y Bru, Escuela de Arquitectura Civil (Valencia, Joseph Tomás Lucas, 1738).

6 Benito Bails no transformó ni reflexionó en exceso sobre las propuestas teatrales de Patté. Se dedicó a reproducir la plancha y el texto del tratadista francés de manera casi mimética: Pedro Navascués Palacio, "Estudio Crítico", Benito Bails, De la arquitectura Civil (Murcia, Colegio Oficial de Aparejadores y Arquitectos Técnicos de Murcia, 1975), 120.

7 José Ortiz y Sanz, traductor de Palladio y Milizia y gran conocedor de Vitruvio publicó en 1807 un interesante trabajo sobre el teatro de Sagunto:
José Ortiz y Sanz, Viage arquitectónicoantiquario de España. Descripción del Teatro Romano de Sagunto (Madrid: Imprenta Real, 1807). Este hecho prueba el interés no solo por el rico pasado arqueológico español sino también por la tipología teatral. Unos años antes, en 1794, Fernando Rodríguez había ofrecido a la Real Academia de San Fernando una serie de dibujos del Teatro de Mérida: José Enrique García Melero, "Los modelos de la tipología del teatro a finales de la llustración en España," Espacio, Tiempo y Forma, Serie VII, Historia del Arte, no. 7 (1994): 222.

8 Un buen ejemplo de esta transición entre el teatro de tradición clásica y el teatro que empezará a extenderse en la época ilustrada con forma de "U" lo tenemos en el Teatro Farnese de Parma, construido por Aleotti entre 1618 y 1628 , si bien es cierto que esta obra se realizó en madera, mientras que las de la llustración se levantarán en materiales más sólidos: García Melero, "Los modelos de la tipología del teatro a finales de la llustración en España," 218.

9 Así lo proponía Benito Bails: "El mejor modo de disponer los palcos es levantar sus diferentes pisos a plomo unos sobre otros, sin pilares que tapen la vista, de modo que formen una fila de balcones. Esta disposición, sobre que tiene nobleza y gracia, es admirable para ver el espectáculo; siendo la figura elíptica de los antepechos aislados de los palcos, igualmente que la de sus paredes testeras muy adecuada para rechazar la voz hacia el medio del corral":Benito Bails, Elementos de Matemáticas, T. IX, Parte Primera (Madrid: Imprenta de la viuda de Ibarra, 1783), 880.

10 Para el caso español fue la corte donde se desarrollaron las experiencias más interesantes al respecto: Ana M. ${ }^{a}$ Arias de Cossío, "La escenografía teatral en el Madrid de Carlos III: un intento de renovación," Anales de Historia del Arte, no. 1 (1989): 265-80 y Ana M. ${ }^{\text {a }}$ Arias de Cossío y Jesús Hernández Pereda, Dos siglos de escenografía en Madrid (Madrid: Mondadori, 1991), 25-58.

${ }^{11}$ Jesús Aguirre y Ortiz de Zárate, El conde Aranda y la reforma de espectáculos en el siglo XVIII, Discurso de Ingreso en la Real Academia Española (Ma- drid: Real Academia Española, 1986), 23. En este sentido, resultan muy útiles estudios como el de Pedro Navascués Palacio para entender la importancia de las relaciones entre las nuevas cajas escénicas y la zona destinada a los espectadores: Pedro Navascués Palacio, "Las máquinas teatrales. Arquitectura y escenografía" en Arquitectura teatral en España. Catálogo de Exposición, ed. MOPU (Madrid: Dirección General de Arquitectura y Vivienda, 1984): 53-64.

12 Archivo de la Real Academia de Bellas Artes de San Fernando (en adelante, ARABASF). Un teatro según los antiguos. 1771, A-3269; A-3270 y A-3271

13 ARABASF. A 3272 a 3276 (VARIOS AUTORES: Hacia una nueva idea de arquitectura (Madrid: Real Academia de Bellas Artes de San Fernando,1992), 94-97).

14 ARSABAF. A 3283 - A 3285.

15 ARSABAF. A 3277 - A 3280.

${ }^{16}$ Gazeta de Madrid (Madrid), noviembre 24, 1778.

17 Archivo Municipal de Burgos (en adelante AMBu.), Exp. 14-294.

18 "Por recelo del fuego, enemigo natural de los teatros se han edificado en Florencia y Bolonia teatros con palcos de piedra y ladrillo; pero se ha experimentado que estos teatros son sordos, y sus bóvedas causan uno como zumbido que perjudica á la limpieza del son. Mas acertado seria hacer de bóveda tabicada los corredores, y de albañilería las paredes testeras de los aposentos, con un revestido interior de madera": Benito Bails, Elementos de Matemáticas, 881

19 "...que la representación de comedias en la forma y por los modos con que oy se practica induce conocida corrupcion de las costumbres y ocasiona muchos daños espirituales y otras tantas ofensas a Dios": AMBu. Exp. 22417.

${ }^{20} \mathrm{AMBu}$. Exps. 22-417 y C2-6$17 / 1$.

${ }^{21}$ AMBu. La-306, fols. 165-168v
${ }^{22}$ AMBu. Exps. 14-294 y 14-296.
${ }_{23}$ Fueron múltiples las esguevas que transcurrían por la ciudad desde el medievo, contribuyendo a sanear su trazado urbanístico: Alberto Cayetano 
Ibáñez Pérez, Burgos y los burgaleses en el siglo XVI (Burgos: Ayuntamiento de Burgos, 1990), 28-31.

${ }^{24} \mathrm{AMBu}$. LA-346, fols. 218- 219 y Exp. 14-294.

${ }^{25}$ AMBu. Exps. 14-296 y 14-294, declaraciones de los maestros el 21 de noviembre y el 15 de diciembre de 1780.

${ }^{26} \mathrm{AMBu}$. Exps. 9-128 y 14-296, documentación de 1781 y declaración de los maestros el 8 de abril de 1782; LA-346, fols. 224-228.

${ }^{27}$ AMBu. LA-346, fols. 185 y $186 v^{\circ} ; 213$ y $218-219$.

${ }^{28}$ AMBu. Exp. 14-299.

${ }^{29} \mathrm{AMBu}$. LA-364, fols. 183-185v .

${ }^{30} \mathrm{AMBu}$. LA-377, fols. 106-107v .

${ }^{31}$ AMBu. LA-377, fols. 137-150v .

${ }^{32} \mathrm{AMBu}$. LA-377, fols. 143-150v'.

${ }^{33} \mathrm{AMBu}$. LA-377, fols. 143-150v .

${ }^{34} \mathrm{AMBu}$. LA-377, fol. $170 \mathrm{v}^{\circ}-173 \mathrm{v}^{\circ}$.

${ }^{35}$ AMBu. LA-386, fol. $168 v^{\circ}-170$ y ARABSAF. Exp. 2-29-1.

${ }^{36}$ AMBu. LA-380, fols. 108-109; LA-386, fols. $168 v^{\circ}-170$ y $186 v^{\circ}-187$ y LA-389, fols. $17 v^{\circ}-20$ y 59-60; Archivo Histórico Nacional (en adelante AHN.) Sección Consejos, Leg. 1114/2 y ARABASF. Signs. 2-29-1 y 139-3, fol. 346v'.
37 AHN. Sección Consejos, Leg. 1114/2; ARABASF. Sign. 139-3, fols. 383 y $387 v^{\circ}$.

${ }^{38} \mathrm{AMBu}$. LA-400, fols. $177 \mathrm{v}^{\circ}-178$; $214 v^{\circ} ; 239 ; 265 v^{\circ} ; 283$ y $283 v^{\circ} ; 290 v^{\circ}-$ $291 v^{\circ} ; 306 v^{\circ}-307 v^{\circ}$ y LA-403, fols. $120-$ $122 v^{\circ}$ y AHN. Sección Consejos, Leg. $1114 / 2$.

${ }^{39}$ AMBu. LA-403, fols. 290-294 y fols. $319 v^{\circ}-320$.

${ }^{40}$ AMBu. Exp. C2-18/11.

${ }^{41}$ ARABASF. Sign. 139-3, fol. 11 y AHN. Sección Consejos, Leg. 1114/2.

${ }^{42}$ AMBu. LA-380, fols. 25-26 y $28 v^{\circ}-29 v^{\circ}$; Exps.18-1214 y 18-810bis, fol. 56.

43 AHN. Sección Consejos. Leg. $1114 / 2$.

${ }^{44}$ AMBu. Exp. 18-810bis, fol. 72.

${ }^{45} \mathrm{AMBu}$. LA-380, fols. 201-202 y Exp.18-1214,

${ }^{46} \mathrm{AMBu}$. Exp.18-1214 y LA-383, fols. $102 v^{\circ}-103 v^{\circ}$

${ }^{47}$ AMBu. Exp.18-1214 y LA-383, fols. $222 v^{\circ}-224$.

${ }^{48}$ AMBu. LA-386, fol. 50.

${ }^{49}$ ARABASF. Signs. 2-29- y 139-3, fol. 11 .

${ }^{50}$ AMBu. LA-386, fol. $168 v^{\circ}-170$ y ARABASF., Sign. 2-29-1.
51 AHN. MPD. 158-161.

52 Las entradas, escaleras, corredores "... parece conducen no á un sitio de divertimiento noble sino a una cárcel y al lupanar más inmundo": Francesco Milizia, El Teatro (Madrid: Imprenta Real, 1789), 173.

53 ARABASF. Un teatro según los antiguos, 1771, A-3269, A-3270, A-3271.

54 "Por ser la vista y el oido los dos sentidos que han de quedar satisfechos [...], la planta de un teatro ha de ser la que mas proporcione á los espectadores, ver y oir bien, y un compuesto de formas ópticas y acústicas el que más coadyuve á este fin...": Benito Bails, Elementos de Matemáticas, 870.

55 "Quando se quiera, formar juicio de un teatro ó coliseo qualquiera por los principios sentados, se supondrán primero, por que toca á la vista, tirados en su planta, desde su mayor anchura, rayos visuales hasta el medio de lo último del foro, y se sabrá qué obstáculos los interceptarán; si los asientos están bien distribuidos; quáles son mejores; desde quales se ve con mas o menos incomodidad...": Benito Bails, Elementos de Matemáticas, 878. 


\section{REFERENCIAS}

Aguirre y Ortiz de Zárate, Jesús. El conde Aranda y la reforma de espectáculos en el siglo XVIII. Discurso de Ingreso en la Real Academia Española. Madrid: Real Academia Española, 1986.

Alier, Roger. "El incendio del teatro de Zaragoza en 1778." Anuario musical 51 (1996): 157164. https://doi.org/10.3989/anuariomusical.1996.i51.313

Álvarez Barrientos, Joaquín. "La Teoría Dramática en la España del Siglo XVIII." Teatro: Revista de Estudios Culturales/A Journal of Cultural Studies 1 (1992): 57-73.

Andioc, René. Teatro y sociedad en el Madrid del siglo XVIII. Madrid: Castalia, 1988.

Arias de Cossío, Ana M. a "La escenografía teatral en el Madrid de Carlos III: un intento de renovación." Anales de Historia del Arte 1 (1989): 265-80.

Arias de Cossío, Ana M. ${ }^{a}$, y Jesús Hernández Pereda. Dos siglos de escenografía en Madrid. Madrid: Mondadori, 1991.

Bails, Benito. Elementos de Matemáticas, T. IX, Parte Primera. Madrid: Imprenta de la viuda de Ibarra, 1783.

Balsalobre García, Juana María. "La arquitectura teatral a través de las pruebas de pensado en la Real Academia de Bellas Artes de San Fernando." Espacio, Tiempo y Forma. Serie VII, Historia del Arte 11 (1998): 261-286. https:// doi.org/10.5944/etfvii.11.1998.2316

Bédat, Claude. La Real Academia de Bellas Artes de San Fernando (1744-1808). Madrid: Fundación Universitaria Española, 1989.

Brizguz y Bru, Athanasio Genaro. Escuela de Arquitectura Civil. Valencia: Joseph Tomás Lucas, 1738.

Cadiñanos Bardeci, Inocencio. "El arquitecto Fernando González de Lara: notas a su vida." Boletín de la Institución Fernán González 204 (1985): 57-78.

Carnero, Guillermo. "Los dogmas neoclásicos en el ámbito teatral." Anales de Literatura Española 10 (1994): 37-67. https://doi. org/10.14198/ALEUA.1994.10.02
Erauso y Zabaleta, Tomás. Discurso crítico sobre el origen, calidad y estado presente de las comedias de España, contra el dictamen que las supone corrompidas, $y$ en favor de sus mas famosos escritores el doctor frey Lope Felix de Vega Capio, y don Pedro Calderón de la Barca. Madrid: Imp. de Zúñiga, 1750.

Frantz, Pierrre. L'esthétique du tableu dans le théâtre du XVIIle siècle, Perspectives Litéraires. Paris: Presses Universitaires de France, 2015.

García Garrosa, M. ${ }^{a}$ Jesús. "La recepción del teatro sentimental francés en España." En Imágenes de Francia en las letras hispánicas: Coloquio celebrado en la Universidad de Barcelona, 15 a 18 de noviembre de 1988, 299305. Barcelona: Promociones y Publicaciones Universitarias, 1989.

García Melero, José Enrique. "Los modelos de la tipología del teatro a finales de la llustración en España." Espacio, Tiempo y Forma, Serie VII, Historia del Arte 7 (1994): 213-246. https://doi.org/10.5944/etfvii.7.1994.2239

González Moreno-Navarro, José Luis. El legado oculto de Vitruvio. Madrid: Alianza Editorial, 1993.

Hermosilla, José de. Architectura civil. BNE, Mss./7573, 1750.

Hernández Sánchez, Mario. "La polémica de los autos sacramentales en el siglo XVIII: la llustración frente al Barroco." Revista de Literatura 42, no. 84 (1989):185-220.

Ibáñez Pérez, Alberto Cayetano. "La iglesia de San Juan de Huérmeces (Burgos) obra del arquitecto Fernando González de Lara." Boletín de la Institución Fernán González 186 (1976): 813-18.

Ibáñez Pérez, Alberto Cayetano. Historia de la Academia de Dibujo de Burgos. Burgos: Diputación Provincial de Burgos, 1982.

Ibáñez Pérez, Alberto Cayetano. Burgos y los burgaleses en el siglo XVI. Burgos: Ayuntamiento de Burgos, 1990.

Iglesias Rouco, Lena Saladina. Arquitectura y urbanismo de Burgos bajo el Reformismo llustrado (1747-1813). Burgos: Caja de Ahorros Municipal de Burgos, 1978. 
Iglesias Rouco, Lena Saladina. "Fernando González de Lara." En Diccionario Biográfico Español, XXIV, 94-95. Madrid: Real Academia de la Historia, 2011.

Iglesias Rouco, Lena Saladina, y M. ${ }^{a}$ José Zaparaín Yáñez. "Los puentes burgaleses a través de la documentación 1600-1800." En Puentes singulares de Burgos: unir orillas, abrir caminos, 53-99. Burgos: Diputación Provincial de Burgos, 2018.

Jovellanos, Gaspar Melchor de. Memoria para el arreglo de la policía de los espectáculos y diversiones públicas y sobre su origen en España. Madrid: Ediciones Cátedra, 1983.

León Tello, Francisco, y M. ${ }^{a}$ Virginia Sanz Sanz. Estética y Teoría de la Arquitectura en los tratados españoles del siglo XVIII. Madrid: Consejo Superior de Investigaciones Científicas, 1994.

Miguel Gallo, Ignacio Javier de. "El patio de comedias de Burgos (1587-1650)." Cuadernos de teatro clásico 6 (1991): 249-264.

Miguel Gallo, Ignacio Javier de. "El proceso de consolidación del teatro en Burgos (15501605). Miguel Giginta y la Casa de Niños de la Doctrina." Bullentin hispanique 94, no. 1 (1992): 45-74. https://doi.org/10.3406/hispa.1992.4758

Miguel Gallo, Ignacio Javier de. El teatro en Burgos (1550-1752): el patio de comedias, las compañías y la actividad escénica: estudio y documentos. Burgos: Ayuntamiento de Burgos, 1994.

Milizia, Francesco. Del Teatro. Venezia: Giambatista Pasquali, 1773.

Milizia, Francesco. Principi di Architettura civile, T. II. Finale, 1781.

Milizia, Francesco. El Teatro. Madrid: Imprenta Real, 1789.

Monleón Gavilanes, Pedro. Juan de Villanueva. Madrid: Akal, 1988.

Navascués Palacio, Pedro. "Estudio Crítico", Benito Bails, De la arquitectura Civil. Murcia: Colegio Oficial de Aparejadores y Arquitectos Técnicos de Murcia, 1975.

Navascués Palacio, Pedro. "Las máquinas teatrales. Arquitectura y escenografía." En Arqui- tectura teatral en España. Catálogo de Exposición, 53-64. Madrid: Dirección General de Arquitectura y Vivienda, 1984.

Navascués Palacio, Pedro. La plaza mayor en España. Ávila: Fundación Cultural Santa Teresa, Instituto de Arquitectura Juan de Herrera, 2002.

Nieto Plaza, Ana Berta. "La obra de la puerta de Santa María en la catedral de Burgos (17901791)." Boletín de la Institución Fernán González 219 (1999): 339-76.

Ortiz y Sanz, José. Viage arquitectónico-antiquario de España. Descripción del Teatro Romano de Sagunto. Madrid: Imprenta Real, 1807.

Payo Hernanz, René Jesús. El retablo en Burgos y su comarca durante los siglos XVII y XVIII. Burgos: Diputación Provincial de Burgos, 1997.

Payo Hernanz, René Jesús. El artista burgalés en la época ilustrada. Burgos: Institución Fernán González, 2005.

Payo Hernanz, René Jesús. Historia de las Casas Consistoriales de Burgos. Burgos: Instituto Municipal de Cultura. Ayuntamiento de Burgos, 2007.

Peruarena Arregui, Juan. "Entre el debate internacional y la adherencia de la tradición o sobre la arquitectura teatral española en el siglo XVIII." Cuadernos de Ilustración y Romanticismo 19 (2013): 221-51. https://doi.org/10.25267/ Cuad_llus_Romant.2013.i19.13

Pevsner, Nikolaus. Historia de las tipologías arquitectónicas. Barcelona: Gustavo Gili, 1979.

Quintana Martínez, Alicia. La arquitectura y los arquitectos de la Real Academia de Bellas Artes de San Fernando (1744-1774). Madrid: Xarait, 1983.

Rodríguez Ruiz, Delfín. "De la utopía a la Academia. El tratado de Architectura Civil de José Hermosilla." En Ensayos de Historia de la Arquitectura del siglo XVIII en España, 267-311. Madrid: Ediciones Complutense, 2019.

Rodríguez Ruiz, Delfín. "La sombra de un edificio. El Escorial en la cultura arquitectónica española durante la época de los primeros borbones (1700-1770)." En Ensayos de Historia de la 
Arquitectura del siglo XVIII en España, 403-50. Madrid: Ediciones Complutense, 2019.

Rodríguez Ruiz, Delfín, y Carlos Sambricio. “El conde de Aranda y la arquitectura española de la llustración." En Catálogo de Exposición El conde de Aranda, 147-71. Zaragoza: Ibercaja, 1998.

Rodríguez Sánchez de León, M. ${ }^{a}$ José. "La teoría del gusto y la constitución del realismo burgués en el siglo XVIII." Res Pública 23 (2010): 37-55.

Sambricio, Carlos. "Francisco Milizia. Principios de Arquitectura," Revista de Ideas Estéticas 132 (1975): 75.

Sambricio, Carlos. La arquitectura española de la Ilustración. Madrid: Consejo Superior de los Colegios de Arquitectos de España, Instituto de Estudios de Administración Local, 1986.

Sambricio, Carlos, y Maira Herrero. "Las intervenciones de Juan de Villanueva en el Real Sitio de San Lorenzo del Escorial," Fragmentos 12, 13, 14 (1988): 189-205.
Soria Tomás, Guadalupe. "La Junta de Reforma de Teatros y la instrucción actoral (17991804)." Acotaciones 23 (2009): 9-32.

Varios Autores. Hacia una nueva idea de arquitectura. Madrid: Real Academia de Bellas Artes de San Fernando, 1992.

Varios Autores. El teatro europeo en la España del siglo XVIII. Lleida: Ediciones de la Universidad de Lleida, 1997.

Viamonte Lucientes, Ernesto. "El coliseo de Zaragoza en llamas. Óleo de Goya y signo de su tiempo." En Goya y su contexto. Actas del Seminario Internacionalcelebrado en la Institución los días 27, 28 y 29 de octubre de 2011, 93-111. Zaragoza: Institución Fernando El Católico, 2013.

Vieites, Manuel F. "Ilustración, educación y teatro en España a finales del siglo XVIII. Algunas claves." Espacio, Tiempo y Educación 6, no. 1 (2019): 199-224. https://doi.org/10.14516/ ete. 194 